\title{
Characteristics of helical flow in slim holes and calculation of hydraulics for ultra-deep wells
}

\author{
Fu Jianhong ${ }^{1 *}$, Yang Yun ${ }^{2}$, Chen Ping ${ }^{1}$ and Zhao Jinhai ${ }^{3}$ \\ ${ }^{1}$ State Key Laboratory of Oil and Gas Reservoir Geology and Exploitation, Southwest Petroleum University, Chengdu, \\ Sichuan 610500, China \\ ${ }^{2}$ Changqing Engineering Technology Research Institute, Chuanqing Drilling Engineering Company Limited, Xi'an, Shaanxi \\ 710021, China \\ ${ }^{3}$ Drilling Technology Research Institute, SINOPEC Shengli Oilfield, Dongying, Shandong 257017, China \\ (c) China University of Petroleum (Beijing) and Springer-Verlag Berlin Heidelberg 2010
}

\begin{abstract}
Due to the slim hole at the lower part of the ultra-deep and deep wells, the eccentricity and rotation of drill string and drilling fluid properties have great effects on the annular pressure drop. This leads to the fact that conventional computational models for predicting circulating pressure drop are inapplicable to hydraulics design of deep wells. With the adoption of helical flow theory and H-B rheological model, a computational model of velocity and pressure drop of non-Newtonian fluid flow in the eccentric annulus was established for the cases where the drill string rotates. The effects of eccentricity, rotation of the drill string and the dimensions of annulus on pressure drop in the annulus were analyzed. Drilling hydraulics was given for an ultra-deep well. The results show that the annular pressure drop decreases with an increase in eccentricity and rotary speed, and increases with a decrease in annular flow area. There is a great difference between static mud density and equivalent circulating density during deep well drilling.
\end{abstract}

Key words: Ultra-deep well, slim hole, annular velocity, annular pressure drop, hydraulics

\section{Introduction}

With further exploration and development of oil and gas, more and more deep and ultra-deep wells are being drilled. Hydraulics design of deep and ultra-deep wells are significantly different from conventional wells due to complicated casing program and slim holes at the lower part of the wells. In the small annulus in a deep well, both eccentricity and rotation of the drill string have great effects on annular pressure drop; and there is a great difference between the drilling fluid density and equivalent circulating density (ECD). The characteristics of circulating fluid flowing in the slim holes of deep wells may cause some difficulties in optimization of the deep well hydraulics. A number of studies of the flow mechanism of non-Newtonian fluids in slim holes have been made over the years (Delwiche et al, 1992; McCann et al, 1995; Cui and Liu, 1996; Zheng, 1998; Wang et al, 2000; Yao and Samuel, 2008). However, the models proposed by previous researchers do not take into account the effects of pipe rotation, eccentricity, and the annular dimensions on annular pressure drop simultaneously. Long et al (2005) and Demirdal and Cunha (2007) studied the effects of non-Newtonian fluids and rheological models on annular

*Corresponding author. email: fujianhong@126.com

Received May 6, 2009 pressure drop. Singhal et al (2005), Chang et al (2007) and Cui et al (2008) studied the effects of eccentricity on annular pressure drop. Marken et al (1992), Cartalos et al (1996), He (2005) and Ma (2006) studied the effects of eccentricity and drill string rotation on annular pressure drop by experimental models. No great progress in the effects of drill string rotation on the velocity and pressure fields in the narrow annulus has been made.

\section{Helical flow characteristics in slim holes}

\subsection{Basic characteristics}

Compared with conventional drilling, deep slimhole drilling is characterized by the slim hole and very slim annulus. Therefore, the annular dimensions, and the rotation and eccentricity of the drill string have significant effects on the pressure drop and velocity distribution in the annulus. The computational model of fluid flow and related technology adopted in conventional drilling are not applicable to the cases of deep slimhole drilling. It is critical to develop a pressure drop model and a velocity distribution model for an accurate prediction of drilling fluids flowing in the drill string and the slim annulus. Figs. 1 and 2 are the cross-sectional views of the annulus and the drill string, respectively. The inner radius and outer radius of the annulus are $R_{\mathrm{i}}$ and $R_{\mathrm{o}}$, and 
the inner radius of the drill string is $R_{\mathrm{d}}$. The drill string rotates at an angular speed of $\Omega$ while the borehole wall or casing wall keeps still. The eccentric distance between the drill string and the annulus is $e$ and $\varepsilon$ is the dimensionless eccentricity, $\varepsilon=\frac{e}{R_{\mathrm{o}}-R_{\mathrm{i}}}$

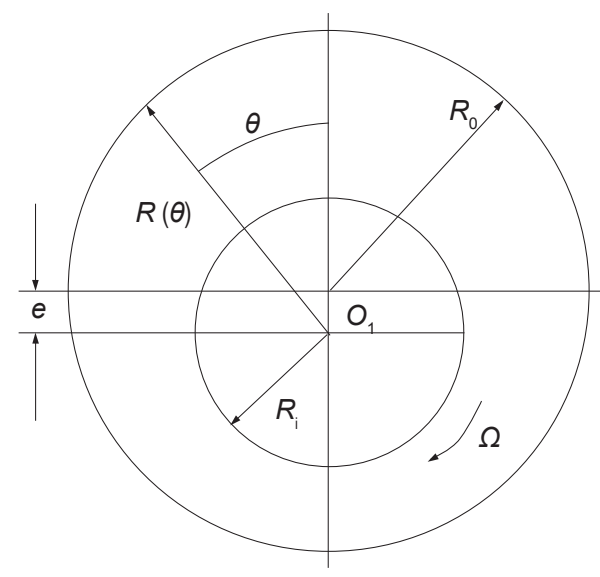

Fig. 1 Flow cross section in the eccentric annulus

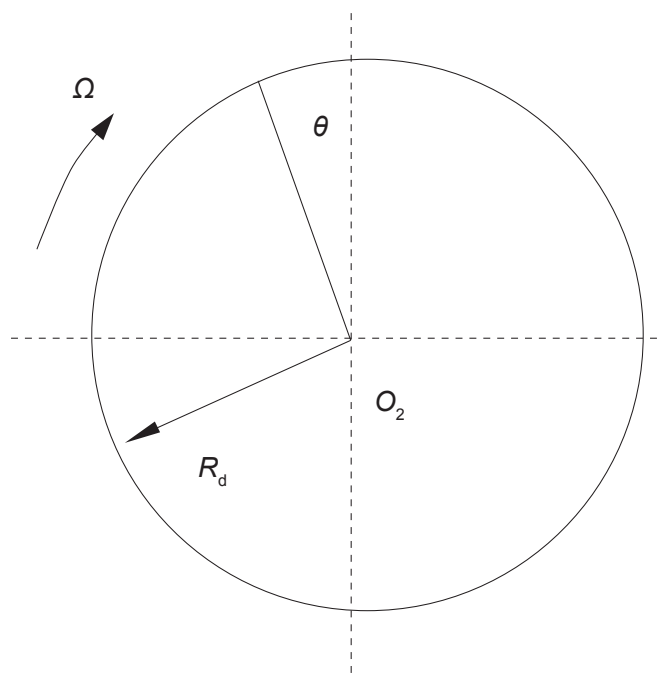

Fig. 2 Flow cross section inside the drill string

\subsection{Velocity distribution in the annulus}

Based on the continuity equation and equation of motion when fluid flows in the laminar flow regime and the constitutive equation of a Herschel-Bulkley (H-B) fluid, in the polar coordinate system (see Fig. 1), the axial velocity $u(r)$ and the angular velocity $\omega(r)$ of the drilling fluid at any position $(r, \theta)$ in the annulus can be deduced as follows:

$$
u(r)= \begin{cases}\int_{R_{\mathrm{i}}}^{r} \frac{1}{\eta}\left(\frac{P_{z} \cdot r}{2}+\frac{C}{r}\right) \mathrm{d} r & R_{\mathrm{i}} \leq r<r_{\mathrm{pi}} \\ \int_{R_{\mathrm{o}}}^{r} \frac{1}{\eta}\left(\frac{P_{z} \cdot r}{2}+\frac{C}{r}\right) \mathrm{d} r & r_{\mathrm{po}}<r \leq R_{\mathrm{o}} \\ \int_{R_{\mathrm{i}}}^{r_{\mathrm{pi}}} \frac{1}{\eta}\left(\frac{P_{z} \cdot r}{2}+\frac{C}{r}\right) \mathrm{d} r & r_{\mathrm{pi}} \leq r \leq r_{\mathrm{po}}\end{cases}
$$

$$
\omega(r)= \begin{cases}\int_{R_{\mathrm{i}}}^{r} \frac{1}{\eta}\left(-\frac{1}{3} \rho g \sin \alpha \sin \theta+\frac{B}{r^{3}}\right) \mathrm{d} r+\Omega & R_{\mathrm{i}} \leq r<r_{\mathrm{pi}} \\ \int_{R_{\mathrm{o}}}^{r} \frac{1}{\eta}\left(-\frac{1}{3} \rho g \sin \alpha \sin \theta+\frac{B}{r^{3}}\right) \mathrm{d} r & r_{\mathrm{po}}<r \leq R_{\mathrm{o}} \\ \int_{R_{\mathrm{i}}}^{r_{\mathrm{pi}}} \frac{1}{\eta}\left(-\frac{1}{3} \rho g \sin \alpha \sin \theta+\frac{B}{r^{3}}\right) \mathrm{d} r+\Omega & r_{\mathrm{pi}} \leq r \leq r_{\mathrm{po}}\end{cases}
$$

Boundary condition: The angular velocity at the inner wall of the annulus is $\omega\left(R_{\mathrm{i}}\right)=\Omega$ and the angular velocity at the outer wall of the annulus is $\omega\left(R_{\mathrm{o}}\right)=0$.

$P_{\mathrm{z}}$ is the pressure gradient, $\mathrm{Pa} / \mathrm{m} ; \eta$ is the apparent viscosity of $\mathrm{H}-\mathrm{B}$ flow, $\mathrm{Pa} \cdot \mathrm{s} ; r_{\mathrm{pi}}$ is the internal boundary of the flow core in the annulus, $\mathrm{m} ; r_{\mathrm{po}}$ is the external boundary of the flow core in the annulus, $\mathrm{m} ; r$ is the radial coordinate, $\mathrm{m} ; \theta$ is the angle in degrees; $\Omega$ is the angular speed of the drill string, $\mathrm{rad} / \mathrm{s} ; \rho$ is the fluid density, $\mathrm{kg} / \mathrm{m}^{3} ; \alpha$ is the inclination; $B$ and $C$ are integration constants; $g$ is the acceleration of gravity, $\mathrm{m} / \mathrm{s}^{2}$.

\subsection{Apparent viscosity distribution in the annulus}

The apparent viscosity $\eta(r)$ of the fluids at any position in the annulus can be derived from constitutive equations of an H-B fluid, the axial velocity, and the angular velocity.

$$
\eta(r)=\frac{K^{\frac{1}{n}}\left[\left(\frac{1}{3} G_{\theta} r+\frac{B}{r^{2}}\right)^{2}+\left(\frac{1}{2} P_{z} r+\frac{C}{r}\right)^{2}\right]^{\frac{1}{2}}}{\left\{\left[\left(\frac{1}{3} G_{\theta} r+\frac{B}{r^{2}}\right)^{2}+\left(\frac{1}{2} P_{z} r+\frac{C}{r}\right)^{2}\right]^{\frac{1}{2}}-\tau_{0}\right\}^{\frac{1}{n}}}
$$

with

$$
G_{\theta}=-\rho g \sin \alpha \sin \theta
$$

where $n$ is the liquidity index; $K$ is the consistency coefficient; $\tau_{0}$ the is yield point, $\mathrm{Pa}$.

\subsection{Annular pressure gradient}

Based on the definition of flow rate, the correlation between the flow rate and the pressure gradient in the annulus can be deduced by integrating over the whole annular cross section to flow. The pressure gradient $P_{z}$ then can be expressed as follows:

$$
P_{z}=\frac{Q}{\int_{0}^{\pi}\left(b_{1}+b_{2}+b_{3}\right) \mathrm{d} \theta}
$$

with

$$
\begin{aligned}
& b_{1}=\int_{R_{\mathrm{i}}}^{r_{\mathrm{pi}}(\theta)} \frac{r_{\mathrm{pi}}^{2}(\theta)-r^{2}}{\eta(r, \theta)}\left(\frac{r}{2}+\frac{C(\theta)}{P_{z} r}\right) \mathrm{d} r \\
& b_{2}=\int_{R(\theta)}^{r_{\mathrm{po}}(\theta)} \frac{r_{\mathrm{po}}^{2}(\theta)-r^{2}}{\eta(r, \theta)}\left(\frac{r}{2}+\frac{C(\theta)}{P_{z} r}\right) \mathrm{d} r
\end{aligned}
$$




$$
b_{3}=\int_{R_{\mathrm{i}}}^{r_{\mathrm{pi}}(\theta)} \frac{r_{\mathrm{po}}^{2}(\theta)-r_{\mathrm{pi}}^{2}(\theta)}{\eta(r, \theta)}\left(\frac{r}{2}+\frac{C(\theta)}{P_{z} r}\right) \mathrm{d} r
$$

where $Q$ is the flow rate, $\mathrm{m}^{3} / \mathrm{s} ; r_{\mathrm{pi}}(\theta)$ and $r_{\mathrm{po}}(\theta)$ are the inner and outer radii of flow core at a circumferential angle of $\theta$, $\mathrm{m} ; C(\theta)$ is the integral constant of axial velocity at a random circumferential angle; $\eta(r, \theta)$ is the apparent viscosity of flow cross section at a circumferential angle of $\theta, \mathrm{Pa} \cdot \mathrm{s}$.

Eq. (4) is the model for computing the pressure gradient of the laminar helical flow of H-B fluids in the eccentric annulus.

\subsection{Velocity distribution inside the drill string}

\subsubsection{Angular velocity distribution}

The angular velocity $\omega$ of the helical flow of the H-B fluid inside the drill string is:

$$
\begin{array}{ll}
\omega=\int_{R_{\mathrm{d}}}^{r} \frac{1}{\eta}\left(-\frac{1}{3} \rho g \sin \alpha \sin \theta\right) \mathrm{d} r+\Omega & r_{\mathrm{o}} \leq r \leq R_{\mathrm{d}} \\
\omega_{0}=\int_{R_{\mathrm{d}}}^{r_{0}} \frac{1}{\eta}\left(-\frac{1}{3} \rho g \sin \alpha \sin \theta\right) \mathrm{d} r+\Omega & 0 \leq r \leq r_{0}
\end{array}
$$

where $\omega_{\mathrm{o}}$ is the angular velocity at the flow core, $\mathrm{rad} / \mathrm{s} ; r_{0}$ is the radius of the flow core, $\mathrm{m}$.

\subsubsection{Axial velocity distribution}

The velocity of the axial flow inside the drill string is:

$$
\begin{array}{r}
u=\frac{n P_{z}}{2(n+1) K^{\frac{1}{n}} x^{2}}\left[\left(x r-\tau_{0}\right)^{\frac{n+1}{n}}-\left(x R_{\mathrm{d}}-\tau_{0}\right)^{\frac{n+1}{n}}\right] \\
r_{0} \leq r \leq R_{\mathrm{d}} \\
u=\frac{n P_{z}}{2(n+1) K^{\frac{1}{n}} x^{2}}\left[\left(x r-\tau_{0}\right)^{\frac{n+1}{n}}-\left(x R_{\mathrm{d}}-\tau_{0}\right)^{\frac{n+1}{n}}\right] \\
r_{0} \leq r \leq R_{\mathrm{d}}
\end{array}
$$

with

$$
x=\sqrt{\frac{G_{\theta}^{2}}{9}+\frac{P_{z}^{2}}{4}}
$$

where $u$ is the axial flow velocity inside the drill string, $\mathrm{m} / \mathrm{s}$; $u_{0}$ is the flow velocity inside the flow core, $\mathrm{m} / \mathrm{s}$.

\subsection{Pressure gradient inside the drill string}

Based on the definition of flow rate, the relationship between the flow rate and the pressure gradient inside the drill string can be deduced by integrating over the whole flow cross section of the drill string. The pressure gradient $P_{\mathrm{z}}$ is as follows:

$$
P_{z}=\frac{Q(n+1) K^{\frac{1}{n}}}{n \int_{0}^{\pi} \frac{1}{x^{4}}\left(x R_{\mathrm{d}}-\tau_{0}\right)^{\frac{n+1}{n}}\left[\frac{n x R_{\mathrm{d}}}{2 n+1}\left(x R_{\mathrm{d}}-\tau_{0}\right)-\frac{n^{2}\left(x R_{\mathrm{d}}-\tau_{0}\right)^{2}}{(2 n+1)(3 n+1)}-\frac{x^{2} R_{\mathrm{d}}^{2}}{2}\right] \mathrm{d} \theta}
$$

An initial pressure gradient value is assumed and then the pressure gradient $P_{\mathrm{z}}$ can be calculated by iteration.

\section{Annular velocity distribution and factors influencing the pressure gradient}

In deep slimhole drilling, the distributions of velocity and pressure are different from those in conventional drilling due to the very slim annulus. Therefore, it is very important to study the effects of annular dimensions, drill string rotation and eccentricity on the distributions of annular velocity and pressure.

Basic input data for calculation are as follows:

1) Drilling fluid properties

Drilling fluid density: $1.34 \mathrm{~g} / \mathrm{cm}^{3}$; rheological parameters: $\square_{600}=159.5, \square_{300}=100.0, \square_{200}=76, \square_{100}=47.4, \square_{600}=3.6, \square_{3}=2.3$.

\section{2) Dimensions of the annulus}

Hole size: $124.15 \mathrm{~mm}$; outer diameter of the drill string: $63.50,82.55,85.50$, and $107.00 \mathrm{~mm}$, respectively.

3) Drilling parameters

Flow rate: $25 \mathrm{~L} / \mathrm{s}$; rotary speed: 60 and $120 \mathrm{r} / \mathrm{min}$, respectively.

\subsection{Calculation of annular velocity}

Fig. 3(a) and Fig. 3(b) show the annular velocity distributions respectively for the cases of $63.5-\mathrm{mm}$ and $107-\mathrm{mm}$ drill string (inner diameter of the annulus). The hole size is $124.15 \mathrm{~mm}$ (outer diameter of the annulus), the dimensionless eccentricity is 0.5 and the rotary speed is $60 \mathrm{r} / \mathrm{min}$. The annular dimension has a great effect on the distributions of axial velocity and angular velocity over all cross sections. The greater the diameter of the drill stem is, i.e. the smaller the annular clearance is, the higher the maximum axial velocity is.

Fig. 3(b) and Fig. 3(c) depict the effects of the eccentricity of the drill string on the distributions of axial velocity and angular velocity. The greater the dimensionless eccentricity of the drill string is, the bigger the difference in velocity at the wider clearance and the narrower clearance is. If the drill string is located the center of the wellbore (see Fig. 3(c)), the axial velocity and angular velocity around drill string change slightly.

Fig. 3(b) and Fig. 3(d) show that the rotary speed of the drill string has little effect on the axial velocity, but a great effect on the angular velocity. The higher the rotary speed, the greater the angular velocity is. 


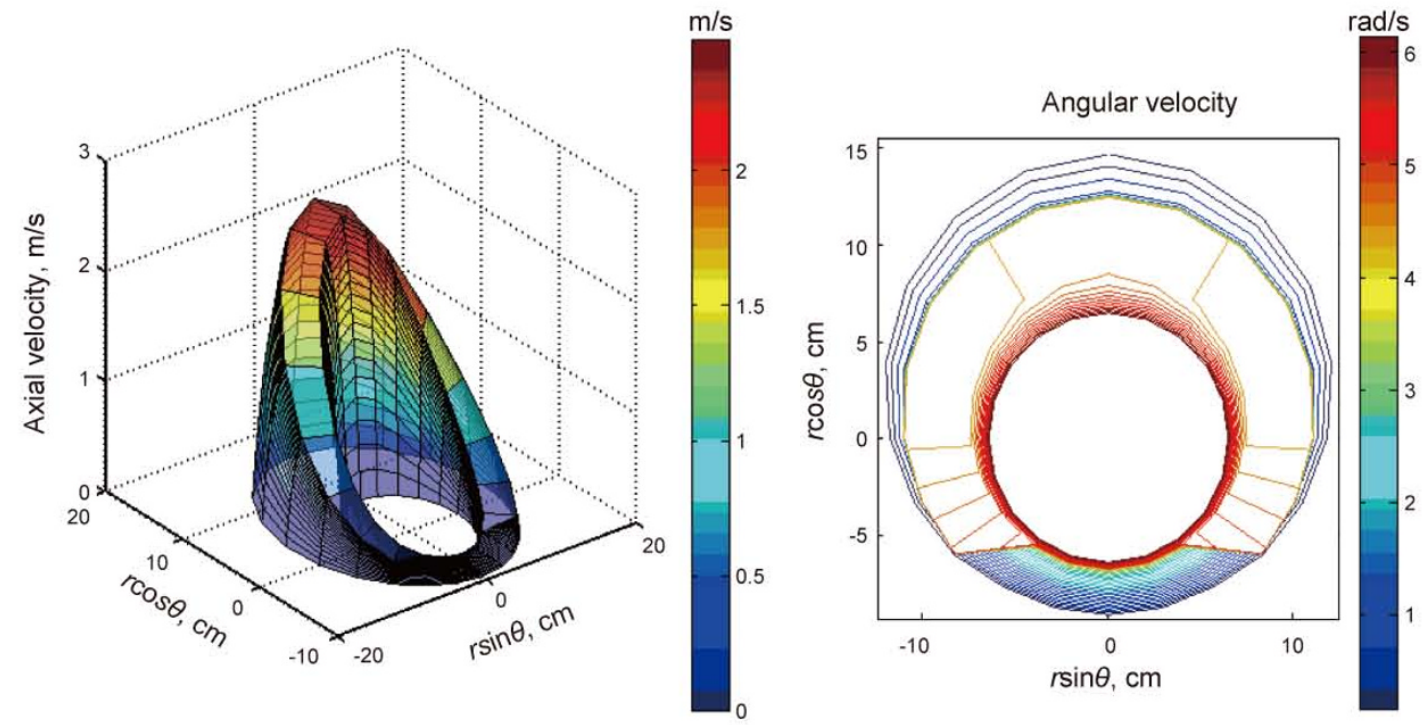

(a) Hole size $124.15 \mathrm{~mm}$; diameter of drill string $63.5 \mathrm{~mm}$; dimensionless eccentricity: 0.5 ; rotary speed: $60 \mathrm{r} / \mathrm{min}$

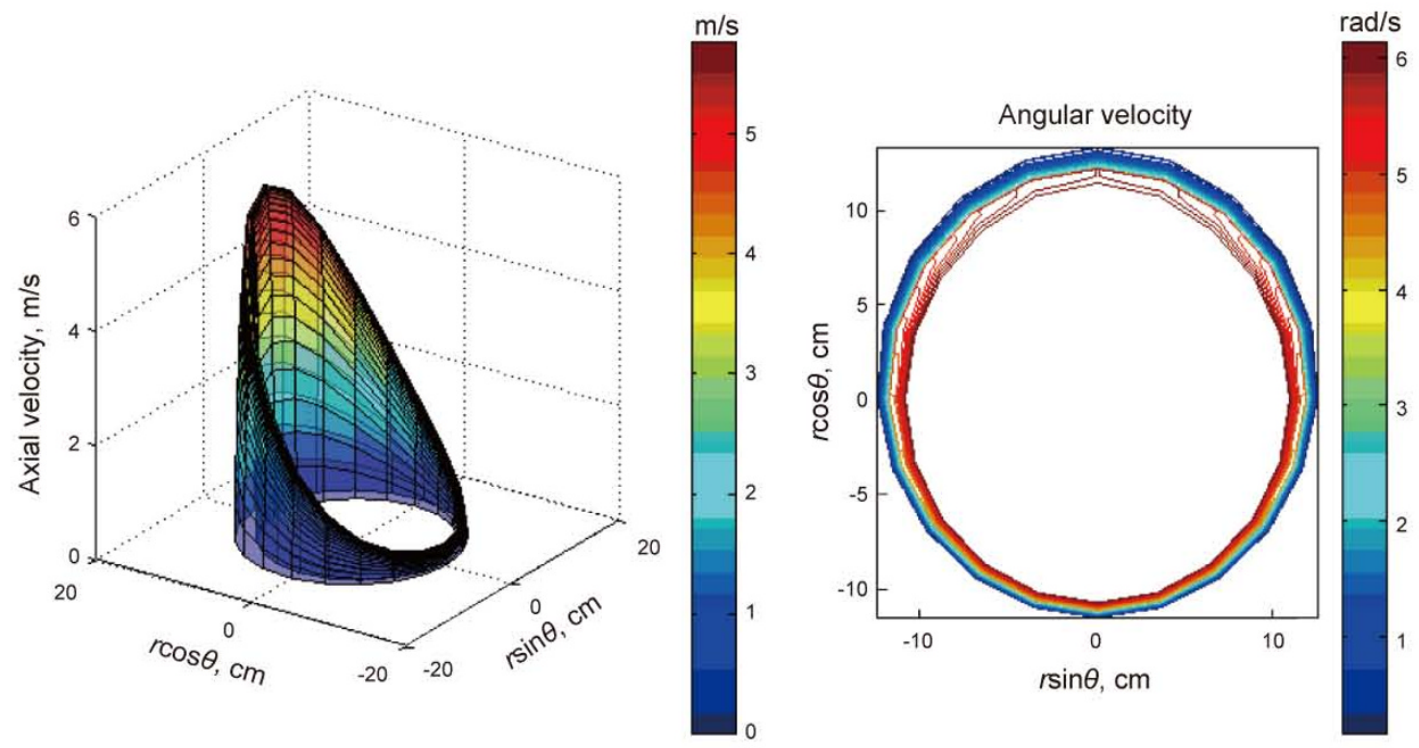

(b) Hole size $124.15 \mathrm{~mm}$; diameter of drill string $107 \mathrm{~mm}$; dimensionless eccentricity: 0.5; rotary speed $60 \mathrm{r} / \mathrm{min}$

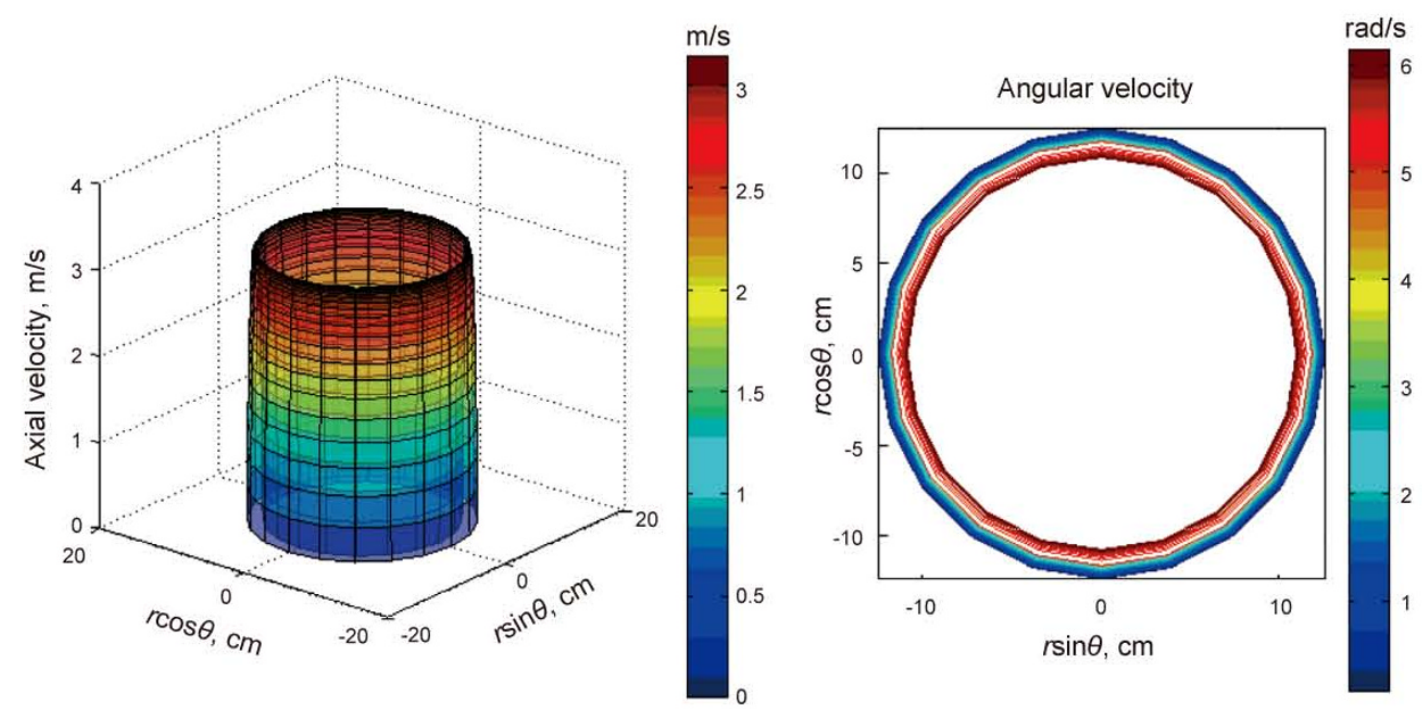

(c) Hole size $124.15 \mathrm{~mm}$; diameter of drill string $107 \mathrm{~mm}$; dimensionless eccentricity 0 ; rotary speed $60 \mathrm{r} / \mathrm{min}$ 


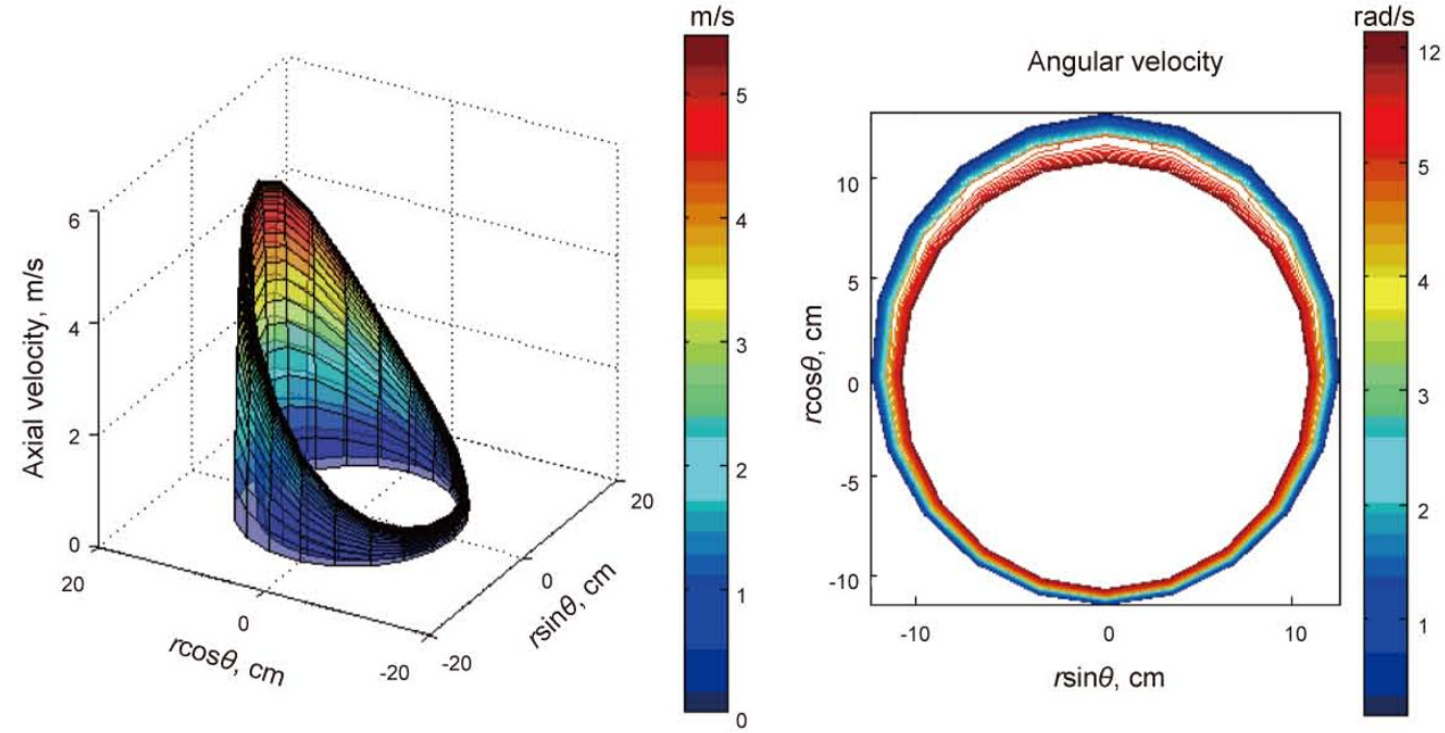

(d) Hole size $124.15 \mathrm{~mm}$; diameter of drilling string $107 \mathrm{~mm}$; dimensionless eccentricity: 0; rotary speed: $120 \mathrm{r} / \mathrm{min}$

Fig. 3 Axial and angular velocity distributions within the annulus

\subsection{Calculation of annular pressure gradient}

Besides the same factors that influence the pressure drop in conventional holes, the eccentricity and rotation of the drill string cannot be neglected because of the small annular clearance in deep slimhole drilling.

Fig. 4 shows the effects of the eccentricity and rotation of the drill string on the annular pressure drop. Simulation results show that for a $107-\mathrm{mm}$ drill string, the pressure gradient in the annulus is high and decreases with an increase in dimensionless eccentricity; but for 63.5-85.5$\mathrm{mm}$ drill strings, drill strings are relatively small, the annular dimension is so big that the eccentricity of the drill string has little influence on the annular pressure drop. The more eccentric the drill strings are, the more the annular pressure losses decrease.

Fig. 5 shows that in drilling rig operations, if the dimensionless eccentricity keeps constant, the rotary speed has a small influence on the annular pressure drop. The smaller the clearance between the wellbore and the drill string, the higher the pressure gradient within the annulus.

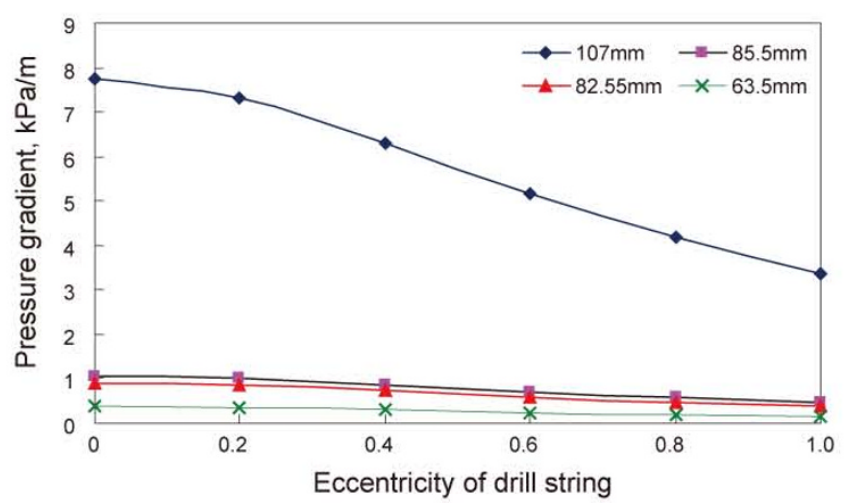

Fig. 4 Effects of the eccentricity of drill string and the annular dimension on the annular pressure drop

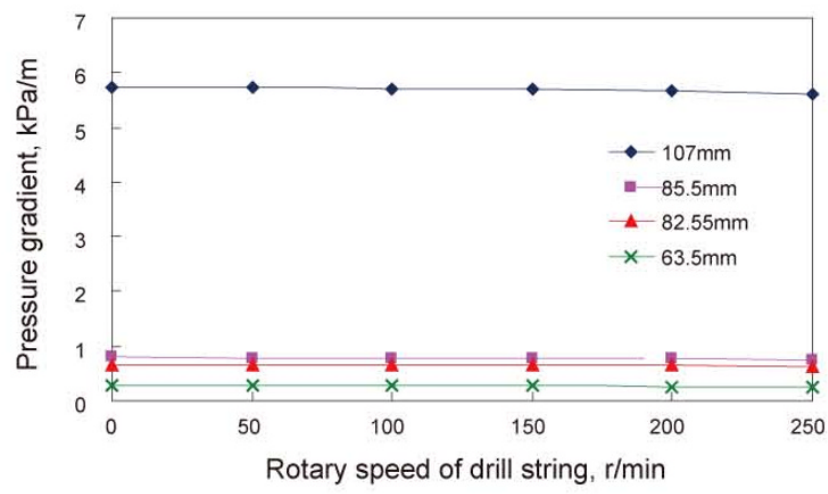

Fig. 5 Effect of rotary speed of drill string on annular pressure drop (Dimensionless eccentricity: 0.5 )

\section{Example of hydraulics design of an ultra- deep well}

Well CK No. 1 is a key ultra-deep well arranged by SINOPEC for exploration of oil and gas in marine strata. The proposed well depth for the $\Phi 212.72 \mathrm{~mm}$ hole size is $7,665 \mathrm{~m}$, the upper $\Phi 250.8 \mathrm{~mm}$ casing is set at a depth of $5,577 \mathrm{~m}$ and is suspended at $3,070 \mathrm{~m}$. Assembly of the drill string: $\Phi 212.72 \mathrm{~mm}$ bit $+\Phi 178$ hydraulic shock absorber $(6 \mathrm{~m})+\Phi 177.8 \mathrm{mmDC} \times 6$ joints $+\Phi 177.8 \mathrm{mmDC} \times 9$ joints $+\Phi 158.8 \mathrm{mmDC} \times 15$ joints $+\Phi 127 \mathrm{~mm} \mathrm{DP}+\Phi 139.7 \mathrm{mmDP}$. Drilling fluid properties measured at surface: density of 1.65 $\mathrm{g} / \mathrm{cm}^{3}$; rheological parameters: $\square_{600}=101, \square_{300}=62, \square_{200}=47$, $\square_{100}=29, \square_{6}=5, \square_{3}=4$. Taking $35 \mathrm{MPa}$ as the rated pump pressure, results of hydraulic design for $\Phi 311.15 \mathrm{~mm}$ borehole and $\Phi 212.72 \mathrm{~mm}$ borehole of Well CK No. 1 are listed in Table 1.

Calculated results (Table 1) show that for the lower part of Well CK No. 1, even if the well size is of large dimension ( $\Phi 212.72 \mathrm{~mm}$ borehole), the annular pressure drop is high due to the long wellbore, which results in a great difference between the static annular pressure and the circulating 
Table 1 Hydraulics design for Well CK No. 1

\begin{tabular}{|c|c|c|c|c|c|c|c|c|c|c|c|}
\hline $\begin{array}{l}\text { Well } \\
\text { depth } \\
\mathrm{m}\end{array}$ & $\begin{array}{c}\text { Bit size } \\
\mathrm{mm}\end{array}$ & $\begin{array}{c}\text { Flow } \\
\text { ratet } \\
\mathrm{L} / \mathrm{s}\end{array}$ & $\begin{array}{l}\text { Mud } \\
\text { density } \\
\mathrm{g} / \mathrm{cm}^{3}\end{array}$ & $\begin{array}{c}\text { Nozzle } \\
\text { combination } \\
\mathrm{mm}\end{array}$ & $\begin{array}{c}\text { Standpipe } \\
\text { pressure } \\
\mathrm{MPa}\end{array}$ & $\begin{array}{c}\text { Bit pressure } \\
\text { drop } \\
\mathrm{MPa}\end{array}$ & $\begin{array}{c}\text { Annular } \\
\text { pressure drop } \\
\mathrm{MPa}\end{array}$ & $\begin{array}{c}\text { Impact } \\
\text { force } \\
\mathrm{kN}\end{array}$ & $\begin{array}{c}\text { Nozzle jet } \\
\text { velocity } \\
\mathrm{m} / \mathrm{s}\end{array}$ & $\begin{array}{l}\text { Hydraulic } \\
\text { power } \\
\text { kW }\end{array}$ & $\begin{array}{l}\text { ECD } \\
\mathrm{g} / \mathrm{cm}^{3}\end{array}$ \\
\hline 3200 & 311.15 & 50 & 2.10 & $14+14+13$ & 34.89 & 15.84 & 0.41 & 12.3 & 116.7 & 714.63 & 2.11 \\
\hline 4000 & 311.15 & 50 & 2.10 & $15+13+13$ & 34.9 & 12.65 & 0.56 & 10.9 & 104.3 & 570.67 & 2.11 \\
\hline 5000 & 311.15 & 50 & 2.10 & $17+15+15$ & 34.91 & 8.67 & 0.72 & 9.1 & 86.3 & 391.16 & 2.11 \\
\hline 5500 & 311.15 & 50 & 2.10 & $18+17+15$ & 34.88 & 6.64 & 0.8 & 7.9 & 75.6 & 299.79 & 2.11 \\
\hline 5600 & 212.72 & 30 & 1.65 & $12+9+8$ & 34.51 & 15.45 & 7.18 & 6.40 & 130.00 & 418.30 & 1.78 \\
\hline 6000 & 212.72 & 30 & 1.65 & $10+10+10$ & 34.91 & 14.84 & 7.70 & 6.30 & 127.40 & 401.74 & 1.78 \\
\hline 6500 & 212.72 & 30 & 1.65 & $12+10+9$ & 34.13 & 12.80 & 8.35 & 5.90 & 118.30 & 346.56 & 1.78 \\
\hline 7000 & 212.72 & 30 & 1.65 & $11+11+10$ & 34.29 & 11.69 & 9.00 & 5.60 & 113.10 & 316.48 & 1.78 \\
\hline 7600 & 212.72 & 30 & 1.65 & $12+10+10$ & 34.77 & 10.66 & 9.77 & 5.30 & 108.00 & 288.52 & 1.78 \\
\hline
\end{tabular}

annular pressure. For drilling deep wells in pressure-sensitive formations, complicated situations such as lost circulation during drilling and well kick during wiper trip should be prevented. As a large hydraulic pressure loss occurs in both the drill pipe and the annulus, optimization of hydraulics parameters should be undertaken when drilling the lower part of deep wells.

\section{Conclusions}

1) Helical flow theory and the H-B rheological model are used to establish a three-dimensional model for predicting velocity distribution in an eccentric annulus. The velocity distribution in the eccentric annulus provides a basis for correct calculation of annular pressure drop.

2) The computational model of pressure drop for nonNewtonian fluids in the eccentric annulus is established, and the effects of the eccentricity, rotation of the drill string and the annular dimensions on annular pressure drop are analyzed. The annular pressure gradient decreases with an increase in the dimensionless eccentricity, and increases with a decrease in the annular flow area.

3) For ultra-deep wells with slim holes, there is a high pressure drop in the annulus and a great difference between the equivalent circulation pressure and the hydrostatic fluid pressure, which brings challenges for safe drilling.

\section{Acknowledgements}

This work is supported by the National 863 Program (2006AA06A19-2).

\section{References}

Cartalos U, King I, Dupuis D, et al. Field validated hydraulic model predictions give guidelines for optimal annular flow in slimhole drilling. Paper SPE 35131 presented at SPE/IADC Drilling Conference held in New Orleans, Louisiana, March 12-15, 1996

Chang Y, Bao Z J, Cui H Q, et al. Pressure gradient of unsteady flow of fluid in an eccentric annulus with the inner cylinder reciprocating axially. Journal of Daqing Petroleum Institute. 2007. 31(6): 40-43 (in Chinese)

Cui H Q and Liu X S. Velocity distribution of non-Newtonian helical flow in eccentric annuli. Acta Petrolei Sinica. 1996. 17(2): 76-83 (in Chinese)

Cui H Q, Zhang S Y, Xiu D Y, et al. Pressure gradient of Newtonian fluid flow in an annulus with the inner cylinder executing planetary motion. Journal of China University of Petroleum. 2008. 32(6): 7678 (in Chinese)

Delwiche R A, Lejeune M, Mawet P, et al. Slimhole drilling hydraulics. Paper SPE 24596 presented at the 67th Annual Technical Conference and Exhibition of SPE held in Washington, D.C., October 4-7, 1992

Demirdal B and Cunha J C. Pressure losses of non-Newtonian fluids in drilling operations. Paper SPE 108711 presented at the 2007 International Oil Conference and Exhibition held in Veracruz, Mexico, June 27-30, 2007

He C C. Computer simulation of power-law fluid and Bingham fluid in an eccentric annulus. Drilling Fluid \& Completion Fluid. 2005. 22(3): 53-56 (in Chinese)

Long Z H, Wang Z M and Guo X L. Correction coefficient method of drilling circulating pressure loss calculation and its application. Natural Gas Industry. 2005. 25(7): 66-68 (in Chinese)

Ma M F. Annular pressure loss and hole cleaning of horizontal wells. West-China Exploration Engineering. 2006. 127(11): 168-170 (in Chinese)

Marken C D, He X J and Saasen A. The influence of drilling conditions on annular pressure losses. Paper SPE 24598 presented at SPE Annual Technical Conference and Exhibition held in Washington, D.C., October 4-7, 1992

McCann R C, Quigley M S, Zamora M, et al. Effects of high-speed pipe rotation on pressures in narrow annuli. SPE Drilling \& Completion. 1995. 10(2): 96-103

Singhal N, Shah S N and Jain S. Friction pressure correlations for Newtonian and non-Newtonian fluids in concentric annuli. Paper SPE 94280 presented at the SPE Production and Operations Symposium held in Oklahoma City, OK, U.S.A., April 17-19, 2005

Wang H G, Su Y N, Bai Y M, et al. Experimental study of slimhole annular pressure loss and its field applications. Paper SPE/IADC 59265 presented at SPE/IADC Drilling Conference held in New Orleans, Louisiana, February 23-25, 2000

Yao D P and Samuel G. Annular-pressure-loss predictions for various standoff devices. Paper SPE 112544 presented at the IADC/SPE Drilling Conference held in Orlando, Florida, U.S.A., March 4-6, 2008

Zheng Y R. Exact solution for helical flow of a non-Newtonian fluid in an annulus. Acta Petrolei Sinica. 1998. 19(2): 91-96 (in Chinese)

(Edited by Sun Yanhua) 